\title{
Pretreatment glycemic control status is an independent prognostic factor for cervical cancer patients receiving neoadjuvant chemotherapy for locally advanced disease
}

Jing Li ${ }^{1,2+}$, Ni-ya Ning ${ }^{3+}$, Qun-xian Rao ${ }^{1}$, Rong Chen ${ }^{4}$, Li-juan Wang ${ }^{1 *}$ and Zhong-qiu Lin ${ }^{1}$

\begin{abstract}
Background: To investigate whether poor glycemic control status has a negative impact on survival outcomes and tumor response to chemotherapy in patients receiving neoadjuvant chemotherapy (NACT) for locally advanced cervical cancer (LACC).

Methods: A retrospective cohort study was conducted to examine LACC patients undergoing NACT and radical hysterectomy between 2002 and 2011. Patients were divided into three groups: patients without diabetes mellitus (DM), diabetic patients with good glycemic control, and diabetic patients with poor glycemic control. Hemoglobin $A_{1 c}\left(H_{b A_{1 c}}\right)$ levels were used to indicate glycemic control status. Recurrence-free survival (RFS), cancer-specific survival (CSS) and overall survival (OS) were analyzed using log-rank tests and Cox proportional hazards models.

Results: In total, 388 patients were included and had a median follow-up time of 39 months (range: 4-67 months). Diabetes mellitus (DM) was diagnosed in 89 (22.9\%) patients, only 35 (39.3\%) of whom had good glycemic control prior to NACT $\left(\mathrm{HbA}_{1 \mathrm{c}}<7.0 \%\right)$. In survival analysis, compared with patients with good glycemic control and patients without DM, patients with poor glycemic control ( $\left.\mathrm{HbA}_{1 c} \geq 7.0 \%\right)$ exhibited decreased recurrence-free survival (RFS), cancer-specific survival (CSS) and overall survival (OS). In multivariate analysis, $\mathrm{HbA}_{1 c} \geq 7.0 \%$ was identified as an independent predictor for decreased RFS (hazard ratio $[H R]=3.33, P<0.0001)$, CSS (HR $=3.60, P<0.0001$ ) and OS $(\mathrm{HR}=4.35, P<0.0001)$. In the subgroup of diabetic patients, $\mathrm{HbA}_{1 \mathrm{c}} \geq 7.0 \%$ prior to NACT had an independent negative effect on RFS (HR $=2.18, P=0.044)$ and $O S(H R=2.29, P=0.012)$. When examined as a continuous variable, the $\mathrm{HbA}_{1 \mathrm{C}}$ level was independently associated with decreased RFS ( $\left.\mathrm{HR}=1.39, P=0.002\right)$, CSS ( $\left.\mathrm{HR}=1.28, P=0.021\right)$ and OS $(\mathrm{HR}=1.27, P=0.004)$. Both good (odds ratio $[\mathrm{OR}]=0.06, P<0.0001)$ and poor glycemic control $(\mathrm{OR}=0.04, P<0.0001)$ were independently associated with a decreased likelihood of complete response following NACT.
\end{abstract}

Conclusions: Poor glycemic control is an independent predictor of survival and tumor response to chemotherapy for patients receiving NACT for LACC.

Keywords: Diabetes mellitus, Hemoglobin $A_{1 c}$ Cervical cancer, Neoadjuvant chemotherapy, Prognosis

\footnotetext{
* Correspondence: wanglijuan_sysu@sina.com

${ }^{\dagger}$ Equal contributors

'Department of Gynecologic Oncology, Sun Yat-sen Memorial Hospital, Sun Yat-sen University, 102 Western Yanjiang Road, Guangzhou 510120, People's Republic of China

Full list of author information is available at the end of the article
} International License (http://creativecommons.org/licenses/by/4.0/), which permits unrestricted use, distribution, and reproduction in any medium, provided you give appropriate credit to the original author(s) and the source, provide a link to the Creative Commons license, and indicate if changes were made. The Creative Commons Public Domain Dedication waiver (http://creativecommons.org/publicdomain/zero/1.0/) applies to the data made available in this article, unless otherwise stated. 


\section{Background}

The Global Cancer Report in 2014 indicates that approximately half of all new cancer cases occur in Asia, mostly in China, and that China's new cancer cases ranked at the top of the list [1]. In fact, the incidence of cancer has been increasing for decades, and cancer is the leading cause of death in China [2]. Tremendous changes in the lifestyle and environment associated with economic development are important contributors to the increased cancer incidence [3]. In addition, these changes have resulted in a sharp increase in the prevalence of diabetes. China has been the country with the largest burden of diabetes worldwide since 2014 [4]. As a common comorbid medical condition, diabetes mellitus (DM) affects $8-18 \%$ of all cancer patients [5]. Previously published data suggest that diabetic patients have worse oncologic outcomes than non-diabetics do [6-13]. Therefore, appropriate diabetic control may have a potential influence for cancer patients.

Cervical cancer is the most common gynecologic malignancy in China [14]. Due to the absence of screening programs, most new cases in China are diagnosed at advanced stages [3]. For cervical cancer patients with locally advanced disease (International Federation of Gynecology and Obstetrics [FIGO] stage IB2 and IIA2), neoadjuvant chemotherapy (NACT) plus radical hysterectomy has been advanced as an effective treatment [15]. A meta-analysis that included 21 randomized trials reported that compared with patients receiving radiotherapy alone patients treated by NACT followed by surgery gain greater survival benefit [16]. Moreover, NACT offers several potential benefits, including eliminating micrometastatic dissemination of the disease and reducing the positivity of lymph nodes, thereby minimizing the need for adjuvant radiotherapy [17-19]. Additionally, for patients with locally advanced cervical cancer (LACC), a complete response (CR) after NACT is independently associated with an improved prognosis [16]. Due to the significant prognostic value, tumor response to NACT has been suggested as a surrogate end-point, which can accurately predict long-term survival outcomes for LACC patients [20].

There are reports that cancer patients with hyperglycemia have a poor response to chemotherapy [6, 21-23]. Moreover, for diabetic cancer patients, poor glycemic control has been observed to negatively influence patient prognosis [7-9, 11, 24]. Among LACC patients, our previous study revealed that hyperglycemia before NACT is an independent predictor of increased risk of relapse and mortality [6]. Despite the evidence, two important questions remain unanswered. Dose adequate blood glucose management offer a survival benefit for LACC patients? Dose glycemic control status impact the response to chemotherapy for LACC patients receiving NACT? Accordingly, we conducted this study to explore whether the glycemic control status influenced oncologic outcomes among LACC patients who underwent NACT and radical hysterectomy.

\section{Methods}

\section{Settings and study population}

After Institutional Review Board approval was obtained from both institutions, a search of clinical databases at Sun Yat-sen Memorial Hospital and the People's Hospital of Shaolin District was performed. All patients with FIGO stage IB2 and IIA2 cervical cancer (histologically confirmed squamous cell carcinoma, adenocarcinoma and adenosquamous carcinoma) who underwent NACT and type III radical hysterectomy from January 1, 2002 to June 30, 2011 were retrospectively reviewed. Pretreatment informed consent was required for all included patients. Patients younger than 16 years as well as patients who had undergone treatment at other hospitals or who had been treated with chemotherapy or radiation therapy for other malignancies or who did not complete the planned cycles of NACT were excluded from the present analysis.

Two to three cycles of NACT were prescribed. Patients underwent type III radical hysterectomy and pelvic lymphadenectomy within 4 weeks after the administration of the last cycle of NACT. CR was defied as no evidence of viable tumor cells in the tumorous area [25]. Post-surgical adjuvant radiotherapy was prescribed according to Sedlis criteria [15]. DM was defined according to the American Diabetes Association diagnostic criteria or a patient-reported history of diabetes [26]. For comparison, patients were classified into three groups: group I (patients without DM), group II (diabetic patients with good glycemic control, hemoglobin $A_{1 c}$ $\left[\mathrm{HbA}_{1 \mathrm{c}}\right]$ levels prior to NACT $<7.0 \%$ ) and group III (diabetic patients with poor glycemic control, $\mathrm{HbA}_{1 \mathrm{c}}$ levels prior to $\mathrm{NACT} \geq 7.0 \%)[10,27]$. If there were multiple $\mathrm{HbA}_{1 \mathrm{c}}$ measurements within 6 months before NACT, the mean value was selected for analysis.

The follow-up was scheduled every 3 months for the first 2 years, then every 6 months for the next 3 years, and every year thereafter. Follow-up visits included complete history, physical examination and Papanicolau smear of the vaginal vault. Follow-up information was obtained from office visits or telephone interviews (Additional file 1: Figure S1. Guide for follow-up and telephone interview). When recurrence was suspected based on clinical findings, imaging studies or biopsies of the suspicious lesions were performed on a case by-case basis.

\section{Statistical analysis}

The primary objective of this study was to determine the association between glycemic control status and recurrence- 
Table 1 Patient demographics

\begin{tabular}{|c|c|c|c|}
\hline & \multirow{2}{*}{$\begin{array}{l}\text { Non-diabetic } \\
\text { patients }(n=299)\end{array}$} & \multicolumn{2}{|l|}{ Diabetic patients $(n=89)$} \\
\hline & & Good Glycemic Control $(n=35)$ & Poor Glycemic Control $(n=54)$ \\
\hline Age, median (range) (years) & $52(24-80)$ & $52(28-72)$ & $52(26-66)$ \\
\hline Body mass index $\left(\mathrm{kg} / \mathrm{m}^{2}\right)$ & $23.2(20.0-28.5)$ & $23.2(19.4-26.7)$ & $23.6(20.8-30.1)$ \\
\hline $\begin{array}{l}\text { Serum creatinine, median (range) } \\
(\mu \mathrm{mol} / \mathrm{l})\end{array}$ & $69(43-100)$ & $71(52-103)$ & $72(44-121)$ \\
\hline \multicolumn{4}{|l|}{ Smoking status, n (\%) } \\
\hline Never & $278(93.0)$ & $33(94.3)$ & $51(94.4)$ \\
\hline Former & $9(3.01)$ & $0(0.0)$ & $1(1.9)$ \\
\hline Current & $1(0.3)$ & $0(0.0)$ & $1(1.9)$ \\
\hline Missing data & $11(3.7)$ & $2(5.7)$ & $1(1.9)$ \\
\hline \multicolumn{4}{|l|}{$\begin{array}{l}\text { Regular cervical cancer screening, } \\
\text { n (\%) }\end{array}$} \\
\hline No & $264(88.3)$ & $29(82.9)$ & $45(83.3)$ \\
\hline Yes & $14(4.7)$ & $4(11.4)$ & $7(13.0)$ \\
\hline Missing data & $21(7.0)$ & $2(5.7)$ & $2(3.7)$ \\
\hline \multicolumn{4}{|l|}{ Cell type, n (\%) } \\
\hline Squamous cell carcinoma & $253(84.6)$ & $30(85.7)$ & $41(75.9)$ \\
\hline Non-squamous cell carcinoma & $46.0(15.4)$ & $5.0(14.3)$ & $13.0(24.1)$ \\
\hline \multicolumn{4}{|l|}{ FIGO stage, n (\%) } \\
\hline IB2 & $253(84.6)$ & $30(85.7)$ & $41(75.9)$ \\
\hline$\| \mathrm{A} 2$ & $46(15.4)$ & $5(14.3)$ & $13(24.1)$ \\
\hline \multicolumn{4}{|l|}{ Grade, n (\%) } \\
\hline G1-2 & $274(91.6)$ & $33(94.3)$ & $49(90.7)$ \\
\hline G3 & $25(8.4)$ & $2(5.7)$ & $5(9.3)$ \\
\hline \multicolumn{4}{|l|}{ Lymph node status, n (\%) } \\
\hline Negative & $202(67.6)$ & $17(48.6)$ & $28(51.9)$ \\
\hline Positive & $97(32.4)$ & $18(51.4)$ & $26(48.2)$ \\
\hline \multicolumn{4}{|l|}{ Parametrial status, n (\%) } \\
\hline Negative & $291(97.3)$ & $33(94.3)$ & $50(92.6)$ \\
\hline Positive & $8(2.7)$ & $2(5.7)$ & $4(7.4)$ \\
\hline \multicolumn{4}{|l|}{ Resection margin, n (\%) } \\
\hline Negative & $292(97.7)$ & $32(91.4)$ & $48(88.9)$ \\
\hline Positive & $7(2.3)$ & $3(8.6)$ & $6(11.1)$ \\
\hline \multicolumn{4}{|l|}{ LVSI, n (\%) } \\
\hline Negative & $156(52.2)$ & $18(51.4)$ & $26(48.2)$ \\
\hline Positive & $143(47.8)$ & $17(48.6)$ & $28(51.9)$ \\
\hline \multicolumn{4}{|l|}{ Deep stromal invasion, n (\%) } \\
\hline No & $97(32.4)$ & $8(22.9)$ & $11(20.4)$ \\
\hline Yes & $202(67.6)$ & $27(77.1)$ & $43(79.6)$ \\
\hline \multicolumn{4}{|l|}{ Hypertension, n (\%) } \\
\hline No & $241(80.6)$ & $19(54.3)$ & $38(70.4)$ \\
\hline Yes & $58(19.4)$ & $16(45.7)$ & $16(29.6)$ \\
\hline \multicolumn{4}{|l|}{ Cardiovascular disease, n (\%) } \\
\hline No & $281(94.0)$ & $30(85.7)$ & $46(85.2)$ \\
\hline Yes & $18(6.0)$ & $5(14.3)$ & $8(14.8)$ \\
\hline
\end{tabular}


Table 1 Patient demographics (Continued)

\begin{tabular}{llll}
\hline Metformin use, $\mathrm{n}(\%)$ & $31(88.6)$ & $37(68.5)$ \\
No & $262(87.6)$ & $4(11.4)$ & $17(31.5)$ \\
Yes & $37(12.4)$ & & $21(38.9)$ \\
Complete response, $\mathrm{n}(\%)$ & & $12(34.3)$ & $33(61.1)$ \\
No & $96(32.1)$ & $23(65.7)$ & $203(67.9)$
\end{tabular}

Abbreviation: FIGO International Federation of Gynecology and Obstetrics, LVSI lymphatic vascular space invasion

free survival (RFS). The secondary objective was to investigate the impact of glycemic control on cancer-specific survival (CSS), overall survival (OS) and the rate of CR. RFS, CSS and OS were calculated from the date of NACT until the date of events (recurrence OR death from cervical cancer OR death from any cause) or the date of last follow-up. The Kaplan-Meier method was used to estimate the RFS, CSS and OS curves. The log-rank test was used to test for differences between curve estimates. For multiple comparisons of survival curves among the three groups, the Bonferroni adjustment was applied. Cox proportional hazards model using with enter method was used to determine independent prognostic factors. Hazard ratios (HRs) and 95\% confidence intervals (CIs) were estimated. The proportional hazards assumption of each variable was verified by Schoenfeld residual plots and no departures from proportionality were observed. Multivariate logistic regression with enter method was used to identify independent variables predicting CR following NACT. Correlations between $\mathrm{CR}$ and assessed variables were expressed as odds ratios (ORs) with 95\% CI. Variables reaching statistical significance at the $P<0.15$ level in the univariate analysis were entered into the multivariate model. All statistical tests were two-sided, and a two-tailed $P$ value $<0.05$ was considered statistically significant. Statistical analyses were performed using software (STATA 10.0, special edition; StataCorp, College Station, TX, USA).

\section{Results}

\section{Patient characteristics}

A total of 388 patients met study criteria. Table 1 summarizes the patient demographics. The median patient age was 52 years (range: 24-80), and the median body mass index (BMI) was $23.2 \mathrm{~kg} / \mathrm{m}^{2}$ (range: 19.430.1). Eighty-nine (22.9\%) patients had DM. Of these diabetic patients, only 35 (39.3\%) had good glycemic control. Group II had three patients with type I DM (8.6\%), while group III had six patients with type I DM (11.1\%) $(P=0.698)$. At baseline, compared with group I, group II and group III had more patients with higher levels of serum creatinine, lymph node metastasis, parametrial involvement, positive surgical margins, lymphatic vascular space invasion (LVSI), deep stromal invasion, hypertension and cardiovascular diseases. In contrast, group II and group III had fewer patients achieving CR following NACT. Among patients with DM, the median $\mathrm{HbA}_{1 \mathrm{c}}$ level was $7.2 \%$ (range: $5.1-12.3 \%$ ). The median $\mathrm{HbA}_{1 \mathrm{c}}$ level for patients in group II was $6.4 \%$ (range: 5.1-6.9\%) compared with $8.3 \%(7.0-12.3 \%)$ for patients in group III $(P=0.0001)$. In addition, compared with patients in group II, group III had more patients with a higher level of BMI and serum creatinine, nonsquamous cell carcinoma, FIGO IIA2 disease, poor differentiated tumor, parametrial involvement, positive surgical margin, LVIS, deep stromal invasion, cardiovascular diseases and history of using metformin use. More patients in group II achieved CR after NACT compared with group III.

\section{Survival outcomes}

After a median follow-up time of 39 months (range: 467 months), recurrence was observed in 72 patients, including $35(11.7 \%)$ patients in group I, 10 (28.6\%) patients in group II and 27 (50\%) patients in group III. The differences in recurrence rate between the three groups were significant $(P<0.0001)$. The median time to tumor recurrence was 18 months (range: 645 months). RFS at 5 years was $87.3 \%, 67.9 \%$ and $45.2 \%$ for patients in group I, group II and group III, respectively. Fig. 1a shows the Kaplan-Meier curves for RFS by diabetic status. Differences between the three survival curves were significant (log-rank test: $X^{2}=62.21$, $P<0.0001)$. A post hoc Bonferroni analysis revealed that the differences in RFS between group I and group II (log-rank test: $\left.\chi^{2}=7.44, P=0.006\right)$, group I and group III (log-rank test: $\chi^{2}=58.76, P<0.0001$ ), and group II and group III (log-rank test: $\left.\chi^{2}=5.85, P=0.016\right)$ were statistically significant. The cumulative CSS at 5 years was $83.5 \%, 61.5 \%$ and $30.3 \%$ for patients in group I, group II and group III, respectively. Fig. 1b displays Kaplan-Meier curves for CSS and significant differences were noted between the curves (log-rank test: $\left.X^{2}=69.18, P<0.0001\right)$. A post hoc Bonferroni analysis showed that the differences in RFS between group I and group II (log-rank test: $X^{2}=7.56, P=0.006$ ), group I and group III (log-rank test: $x^{2}=67.82, P<0.0001$ ), and group II and group III (log-rank test: $X^{2}=6.28$, $P=0.012)$ were statistically significant. The estimated 5- 

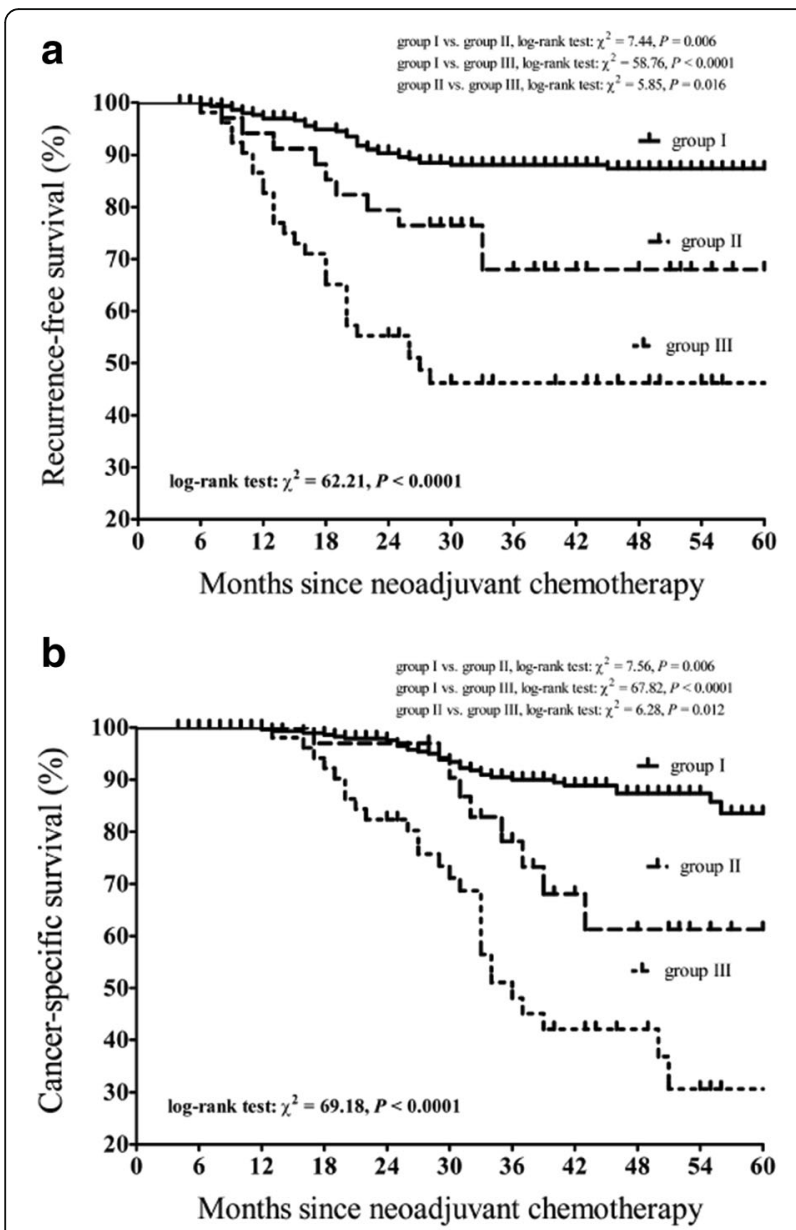

C

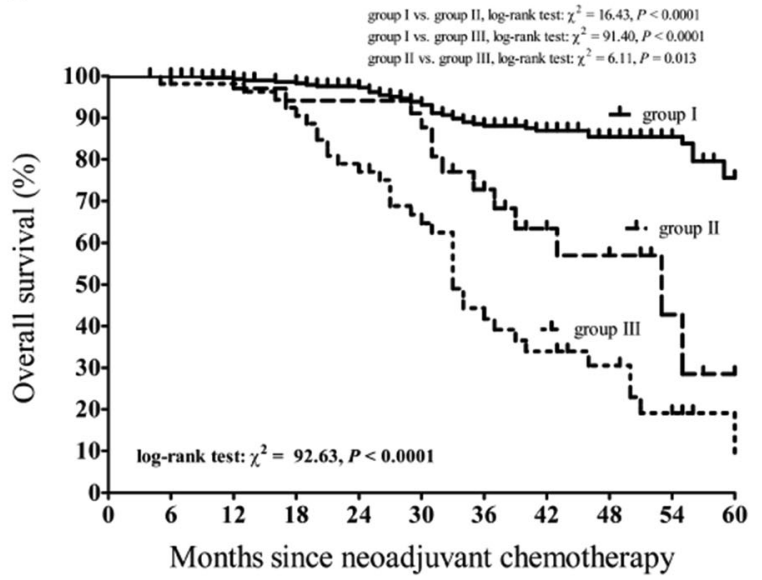

Fig. 1 Kaplan-Meier survival curves for survival of cervical cancer patients treated with neoadjuvant chemotherapy and radical hysterectomy for locally advanced disease. a. Recurrence-free survival. b. Cancer-specific survival. c. Overall survival. Patients were stratified by levels of hemoglobin $A_{1 c}\left(H_{b A_{1 c}}\right)$. The $P$ values were determined by the log-rank test. Group I, patients without diabetes mellitus; group II, patients with well-controlled DM (preoperative $\mathrm{HbA}_{1 c}<7.0 \%$ ); group III, patients with poorly controlled DM (preoperative $\mathrm{HbA}_{1 \mathrm{c}} \geq 7.0 \%$ ) year OS was $60.5 \%, 28.5 \%$ and $9.5 \%$ for patients in group I, group II and group III, respectively. Kaplan-Meier curves for OS are presented in Fig. 1c, and significant differences were noted between the curves (log-rank test: $\left.X^{2}=92.63, P<0.0001\right)$. In the post hoc Bonferroni analysis, differences in OS between group I and group II (log-rank test: $X^{2}=16.43, P<0.0001$ ), group I and group III (log-rank test: $X^{2}=91.40, P<0.0001$ ), and group II and group III (log-rank test: $X^{2}=6.11, P=0.013$ ) were significant.

The results of Cox regression analyses are detailed in Table 2 and Table $3 . \mathrm{HbA}_{1 \mathrm{c}} \geq 7.0 \%$ prior to NACT was identified as an independent predictor of RFS (HR $=3.33$, 95\% CI 1.89-5.88, $P<0.0001)$, CSS (HR $=3.60,95 \%$ CI $1.96-6.61, P<0.0001)$ and OS (HR $=4.35,95 \%$ CI $2.64-$ 7.17, $P<0.0001$ ).

To investigate the survival impact of glycemic control for diabetic patients, we excluded patients without DM and performed a further subgroup analyses. The results of Cox proportional hazard analyses are summarized in Table 4 and Table 5. When the level of $\mathrm{HbA}_{1 \mathrm{c}}$ was treated as a dichotomous variable, $\mathrm{HbA}_{1 \mathrm{c}} \geq 7.0 \%$ prior to NACT exhibited an independent negative effect on RFS (HR $=2.18,95 \%$ CI 1.02-4.63, $P=0.044)$ and OS $(\mathrm{HR}=2.29,95 \%$ CI $1.20-4.35, P=0.012)$. When the $\mathrm{HbA}_{1 \mathrm{c}}$ level was examined as a continuous variable (Additional file 2: Table S1), it was independently associated with RFS (HR $=1.39$, 95\% CI 1.13-1.71, $P=0.002)$, CSS $(\mathrm{HR}=1.28,95 \%$ CI $1.04-1.59, P=0.021)$ and OS $(\mathrm{HR}=1.27,95 \%$ CI $1.08-1.50, P=0.004)$.

\section{Factors predicting CR after NACT}

$\mathrm{CR}$ following NACT has been validated as an accurate surrogate endpoint of survival for LACC patients. Given its significance, a further logistic regression analysis was conducted to identify variables that could predict $\mathrm{CR}$ after NACT. Table 6 presents the results. Both good glycemic control $(\mathrm{OR}=0.06,95 \% \mathrm{CI} \quad 0.02-0.17$, $P<0.0001)$ and poor glycemic control $(\mathrm{OR}=0.04,95 \%$ CI $0.02-0.11, P<0.0001)$ were identified as independent predictors of decreasing incidence of CR after NACT.

\section{Discussion}

The prevalence of DM is $9.7 \%$ in mainland China, which translates into 92.4 million adults with diabetes [28]. Of patients included in the present study, 89 (22.9\%) had DM, and only $35(39.3 \%)$ diabetic patients had good glycemic control. Our results were consistent with previous reports [5]. Considering the negative impact of $\mathrm{DM}$ on the prognosis for cancer patients, we conducted this study. We found that poor glycemic control $\left(\mathrm{HbA}_{1 \mathrm{c}} \geq 7.0 \%\right)$ was independently associated with an increased risk of tumor recurrence and death in LACC patients who received NACT. In addition, DM patients, 
Table 2 Univariate Cox analysis of prognostic factors associated with survival for patients with locally advanced cervical cancer who underwent neoadjuvant chemotherapy and radical hysterectomy

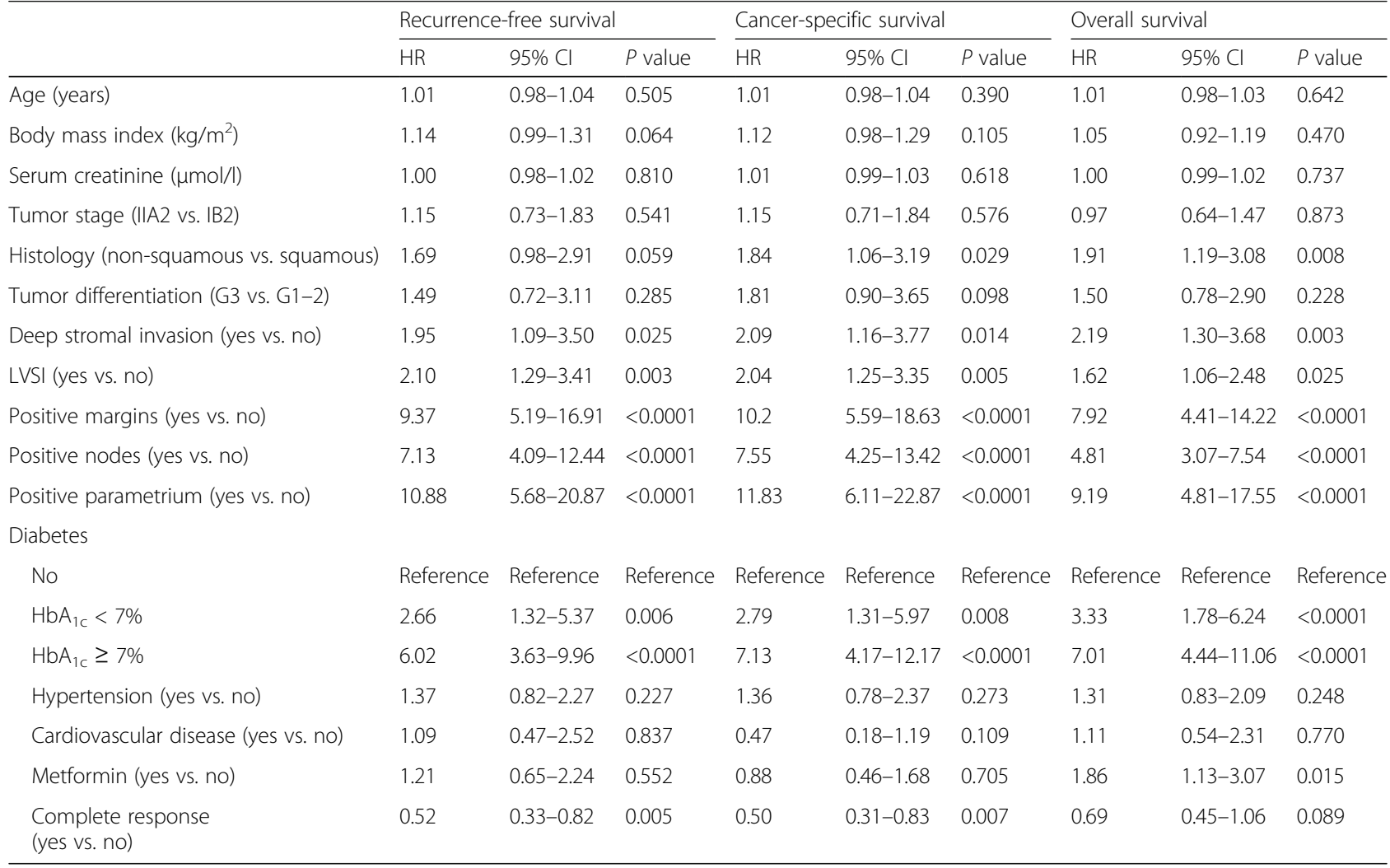

Abbreviation: $\mathrm{Cl}$ confidence interval, $H b A_{1 c}$ hemoglobin $\mathrm{A}_{1 c}, \mathrm{HR}$ hazard ratio, LVSI lymphatic vascular space invasion

regardless of the glycemic control status, were less likely to achieve CR after NACT than were non-diabetics.

Previous studies assessed the influence of glycemic control status on survival outcomes in cancer patients. In diabetic patients receiving curative resection for hepatitis $\mathrm{C}$ virus-related hepatocellular carcinoma, poor glycemic control was an independent predictor of relapse following surgery [8]. In patients with colorectal cancer, poorly controlled DM independently predicted more advanced disease and poor 5-year survival [11]. For patients with early-stage breast cancer, mortality was significantly increased in women with $\mathrm{HbA}_{1 \mathrm{C}} \geq 7.0 \%$ compared with women with $\mathrm{HbA}_{1 \mathrm{C}}$ less than 6.5\% [10]. For patients with urinary system tumors, poor glycemic control was observed as a prognostic factor of poor prognosis $[7,9,12,24]$. For cervical cancer patients, previously published data have suggested a deleterious effect of hyperglycemia on patient survival. However, no study to date has evaluated the survival impact of glycemic control status among cervical cancer patients.

The potential influence of glycemic control on cancer prognosis is complex. Because glucose uptake in cancer cells is significantly enhanced, patients with poorly controlled DM exhibit increased tumor cell proliferation $[29,30]$. Second, as a result of poor glycemic control, hyperglycemia can induce elevated levels of insulin and insulin-like growth and inflammatory factors, which can directly augment tumor progression [10, 31, 32]. Third, poor glycemic control enhances the production of advanced glycosylated end products. Consequently, lipid peroxidation and the production of genotoxic aldehyde can be induced, which result in DNA damage [11]. Fourth, cancer patients with DM frequently have comorbid conditions, which often lead clinicians to follow less aggressive cancer treatments [33, 34]. Additionally, diabetic women underuse cervical cancer screening as compared with non-diabetic women, which may lead to tumor detection at a later stage on diagnosis [35].

For patients with LACC, the prognostic value of $C R$ following NACT has been validated by previous studies. A meta-analysis by $\mathrm{Ye}$ et al. including data from 18 studies reported that response to NACT is an indicator of significantly improved prognosis [16]. Alessandro et al. conducted a retrospective cohort study, which is one of the largest samples of LACC patients with robust follow-up data (median follow-up time: 12.7 years) [20]. They assessed the long-term significance of tumor response to NACT, and reported that CR following NACT could be used as a reliable surrogate end-point, which accurately predicts significantly improved prognosis for LACC patients undergoing NACT. 
Table 3 Multivariate Cox analysis of prognostic factors associated with survival for patients with locally advanced cervical cancer who underwent neoadjuvant chemotherapy and radical hysterectomy

\begin{tabular}{|c|c|c|c|c|c|c|c|c|c|}
\hline & \multicolumn{3}{|c|}{ Recurrence-free survival } & \multicolumn{3}{|c|}{ Cancer-specific survival } & \multicolumn{3}{|c|}{ Overall survival } \\
\hline & $\overline{\mathrm{HR}}$ & $95 \% \mathrm{Cl}$ & $P$ value & $\overline{\mathrm{HR}}$ & $95 \% \mathrm{Cl}$ & $P$ value & $\overline{\mathrm{HR}}$ & $95 \% \mathrm{Cl}$ & $P$ value \\
\hline \multicolumn{10}{|l|}{ Age (years) } \\
\hline Body mass index $\left(\mathrm{kg} / \mathrm{m}^{2}\right)$ & 1.04 & $0.90-1.19$ & 0.621 & 1.03 & $0.89-1.20$ & 0.680 & & & \\
\hline \multicolumn{10}{|l|}{ Serum creatinine $(\mu \mathrm{mol} / \mathrm{l})$} \\
\hline \multicolumn{10}{|l|}{ Tumor stage (IIA2 vs. IB2) } \\
\hline $\begin{array}{l}\text { Histology (non-squamous vs. } \\
\text { squamous) }\end{array}$ & 1.28 & $0.70-2.35$ & 0.427 & 1.30 & $0.68-2.47$ & 0.430 & 1.28 & $0.51-3.21$ & 0.602 \\
\hline Tumor differentiation (G3 vs. G1-2) & & & & 4.16 & $1.93-8.97$ & $<0.0001$ & & & \\
\hline Deep stromal invasion (yes vs. no) & 0.77 & $0.40-1.49$ & 0.433 & 0.83 & $0.42-1.63$ & 0.586 & 1.21 & $0.68-2.16$ & 0.516 \\
\hline LVSI (yes vs. no) & 1.26 & $0.73-2.15$ & 0.405 & 1.16 & $0.66-2.04$ & 0.616 & 0.91 & $0.56-1.48$ & 0.708 \\
\hline Positive margins (yes vs. no) & 3.70 & $1.86-7.35$ & $<0.0001$ & 4.42 & $2.15-9.08$ & $<0.0001$ & 3.26 & $1.69-6.28$ & $<0.0001$ \\
\hline Positive nodes (yes vs. no) & 5.21 & $2.82-9.62$ & $<0.0001$ & 6.67 & $\begin{array}{l}3.47- \\
12.80\end{array}$ & $<0.0001$ & 3.47 & $2.09-5.78$ & $<0.0001$ \\
\hline Positive parametrium (yes vs. no) & 3.37 & $1.67-6.82$ & 0.001 & 3.14 & $1.54-6.41$ & 0.002 & 2.84 & $1.41-5.73$ & 0.004 \\
\hline \multicolumn{10}{|l|}{ Diabetes } \\
\hline No & Reference & Reference & Reference & Reference & Reference & Reference & Reference & Reference & Reference \\
\hline $\mathrm{HbA}_{1 \mathrm{c}}<7 \%$ & 1.49 & $0.69-3.22$ & 0.307 & 1.57 & $0.68-3.62$ & 0.290 & 2.06 & $1.04-4.07$ & 0.039 \\
\hline $\mathrm{HbA}_{1 \mathrm{c}} \geq 7 \%$ & 3.33 & $1.89-5.88$ & $<0.0001$ & 3.60 & $1.96-6.61$ & $<0.0001$ & 4.35 & $2.64-7.17$ & $<0.0001$ \\
\hline \multicolumn{10}{|l|}{ Hypertension (yes vs. no) } \\
\hline Cardiovascular disease (yes vs. no) & & & & 0.57 & $0.22-1.48$ & 0.245 & & & \\
\hline Metformin (yes vs. no) & & & & & & & 1.13 & $0.41-3.11$ & 0.807 \\
\hline Complete response (yes vs. no) & 0.58 & $0.36-0.95$ & 0.031 & 0.52 & $0.31-0.87$ & 0.013 & 0.78 & $0.50-1.22$ & 0.279 \\
\hline
\end{tabular}

Abbreviation: $\mathrm{Cl}$ confidence interval, $H b A_{1 c}$ hemoglobin $\mathrm{A}_{1,}, H R$ hazard ratio, $L V S I$ lymphatic vascular space invasion

Table 4 Univariate Cox analysis of prognostic factors associated with survival for diabetic patients with locally advanced cervical cancer who underwent neoadjuvant chemotherapy and radical hysterectomy

\begin{tabular}{|c|c|c|c|c|c|c|c|c|c|}
\hline & \multicolumn{3}{|c|}{ Univariate analysis } & \multicolumn{3}{|c|}{ Univariate analysis } & \multicolumn{3}{|c|}{ Univariate analysis } \\
\hline & $\overline{\mathrm{HR}}$ & $95 \% \mathrm{Cl}$ & $P$ value & $\mathrm{HR}$ & $95 \% \mathrm{Cl}$ & $P$ value & $\mathrm{HR}$ & $95 \% \mathrm{Cl}$ & $P$ value \\
\hline Age (years) & 1.00 & $0.96-1.04$ & 0.875 & 1.01 & $0.97-1.05$ & 0.681 & 0.99 & $0.96-1.03$ & 0.698 \\
\hline Body mass index $\left(\mathrm{kg} / \mathrm{m}^{2}\right)$ & 1.17 & $0.99-1.39$ & 0.065 & 1.18 & $1.00-1.39$ & 0.055 & 1.08 & $0.92-1.26$ & 0.361 \\
\hline Serum creatinine $(\mu \mathrm{mol} / \mathrm{l})$ & 1.00 & $0.98-1.02$ & 0.872 & 1.02 & $0.99-1.04$ & 0.211 & 1.01 & $0.98-1.03$ & 0.610 \\
\hline Tumor stage (IIA2 vs. IB2) & 2.04 & $1.07-3.90$ & 0.031 & 1.85 & $0.96-3.57$ & 0.065 & 1.44 & $0.82-2.54$ & 0.207 \\
\hline Histology (non-squamous vs. squamous) & 1.31 & $0.62-2.77$ & 0.485 & 1.27 & $0.58-2.80$ & 0.549 & 1.40 & $0.71-2.76$ & 0.332 \\
\hline Tumor differentiation (G3 vs. G1-2) & 0.79 & $0.19-3.30$ & 0.751 & 0.90 & $0.22-3.76$ & 0.888 & 1.07 & $0.33-3.44$ & 0.913 \\
\hline Deep stromal invasion (yes vs. no) & 1.49 & $0.62-3.58$ & 0.371 & 1.55 & $0.68-3.55$ & 0.300 & 1.79 & $0.86-3.70$ & 0.119 \\
\hline LVSI (yes vs. no) & 1.16 & $0.61-2.24$ & 0.647 & 1.26 & $0.65-2.44$ & 0.503 & 0.96 & $0.54-1.70$ & 0.890 \\
\hline Positive margins (yes vs. no) & 3.69 & $1.71-7.97$ & 0.001 & 4.14 & $1.88-9.13$ & $<0.0001$ & 3.04 & $1.42-6.47$ & 0.004 \\
\hline Positive nodes (yes vs. no) & 4.81 & $2.19-10.56$ & $<0.0001$ & 4.12 & $1.87-9.07$ & $<0.0001$ & 3.07 & $1.63-5.78$ & $<0.0001$ \\
\hline Positive parametrium (yes vs. no) & 5.55 & $2.27-13.55$ & $<0.0001$ & 4.76 & $1.95-11.59$ & 0.001 & 3.71 & $1.55-8.89$ & 0.003 \\
\hline Diabetic status $\left(\mathrm{HbA}_{1 \mathrm{c}} \geq 7 \%\right.$ vs. $\left.\mathrm{HbA}_{1 c}<7 \%\right)$ & 2.24 & $1.08-4.63$ & 0.030 & 2.45 & $1.15-5.22$ & 0.020 & 2.17 & $1.15-4.11$ & 0.017 \\
\hline Hypertension (yes vs. no) & 0.90 & $0.46-1.77$ & 0.763 & 0.94 & $0.47-1.86$ & 0.854 & 0.90 & $0.50-1.62$ & 0.723 \\
\hline Cardiovascular disease (yes vs. no) & 0.61 & $0.22-1.73$ & 0.355 & 0.51 & $0.18-1.46$ & 0.211 & 0.68 & $0.30-1.52$ & 0.343 \\
\hline Metformin (yes vs. no) & 0.77 & $0.34-1.75$ & 0.531 & 0.79 & $0.33-1.90$ & 0.595 & 1.22 & $0.62-2.40$ & 0.563 \\
\hline Complete response (yes vs. no) & 0.56 & $0.29-1.07$ & 0.077 & 0.49 & $0.25-0.94$ & 0.033 & 0.74 & $0.41-1.33$ & 0.316 \\
\hline
\end{tabular}


Table 5 Multivariate Cox analysis of prognostic factors associated with survival for diabetic patients with locally advanced cervical cancer who underwent neoadjuvant chemotherapy and radical hysterectomy

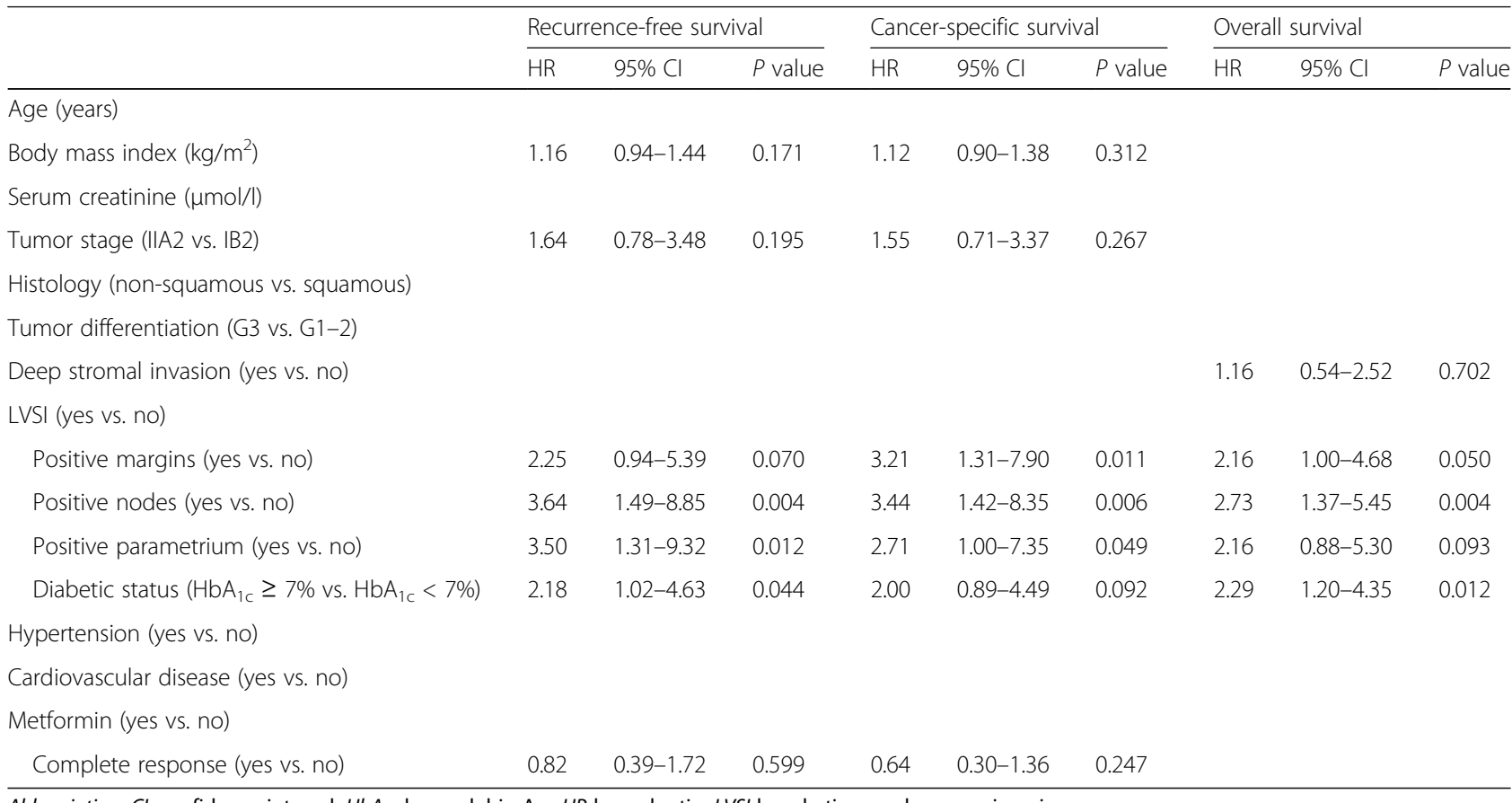

Abbreviation: $\mathrm{Cl}$, confidence interval, $H b A_{1 c}$ hemoglobin $\mathrm{A}_{1 C,}, H R$ hazard ratio, $L V S I$ lymphatic vascular space invasion

The clinical significance of CR following NACT was also confirmed by our study. Moreover, compared with patients without DM, both DM patients with good glycemic control and DM patients with poor glycemic control were less likely to achieve CR. Our findings were in agreement with previous reports, where a poor response to chemotherapy was more frequently observed in patients with hyperglycemia [6, 21-23].

The present study has several limitations. The most important limitation derives from its retrospective design which may have missed confounding factors. For instance, some demographic and lifestyle variables such as patient

Table 6 Univariate and multivariate analysis of predictors of complete response following neoadjuvant chemotherapy in patients with locally advanced cervical cancer who underwent neoadjuvant chemotherapy and radical hysterectomy

\begin{tabular}{|c|c|c|c|c|c|c|}
\hline & \multicolumn{6}{|c|}{ Complete response } \\
\hline & \multicolumn{3}{|c|}{ Univariate analysis } & \multicolumn{3}{|c|}{ Multivariate analysis } \\
\hline & $\mathrm{OR}$ & $95 \% \mathrm{Cl}$ & $P$ value & $\mathrm{OR}$ & $95 \% \mathrm{Cl}$ & $P$ value \\
\hline Age (years) & 1.01 & $0.99-1.04$ & 0.286 & & & \\
\hline Body mass index $\left(\mathrm{kg} / \mathrm{m}^{2}\right)$ & 1.19 & $1.01-1.39$ & 0.037 & 1.27 & $1.04-1.55$ & 0.020 \\
\hline Serum creatinine ( $\mu \mathrm{mol} / \mathrm{l})$ & 0.97 & $0.95-0.99$ & 0.001 & 0.99 & $0.97-1.02$ & 0.573 \\
\hline Tumor stage (IIA2 vs. IB2) & 1.60 & $1.12-2.30$ & 0.010 & 0.99 & $0.73-1.35$ & 0.956 \\
\hline Histology (non-squamous vs. squamous) & 1.55 & $0.64-3.71$ & 0.329 & & & \\
\hline Tumor differentiation (G3 vs. G1-2) & 0.91 & $0.45-1.84$ & 0.784 & & & \\
\hline \multicolumn{7}{|l|}{ Diabetes } \\
\hline No & Reference & Reference & Reference & Reference & Reference & Reference \\
\hline $\mathrm{HbA}_{1 c}<7 \%$ & 0.05 & $0.02-0.14$ & $<0.0001$ & 0.06 & $0.02-0.17$ & $<0.0001$ \\
\hline $\mathrm{HbA}_{1 \mathrm{c}} \geq 7 \%$ & 0.04 & $0.02-0.10$ & $<0.0001$ & 0.04 & $0.02-0.11$ & $<0.0001$ \\
\hline Hypertension (yes vs. no) & 0.34 & $0.20-0.59$ & $<0.0001$ & 0.38 & $0.20-0.74$ & 0.004 \\
\hline Cardiovascular disease (yes vs. no) & 0.84 & $0.35-2.04$ & 0.700 & & & \\
\hline Metformin (yes vs. no) & 0.64 & $0.34-1.22$ & 0.174 & & & \\
\hline
\end{tabular}


income and alcohol habits were not included. In addition, our study did not answer whether the duration of DM and the glycemic control status could impact patient survival. Second, a central pathology review for surgical specimens was not performed. Third, data on $\mathrm{HbA}_{1 \mathrm{c}}$ levels in patients without DM were unavailable. Therefore, some patients in group I might have been true diabetic patients, which could induce selection bias. Fourth, although we assessed the influence of metformin, the effects of other anti-diabetic drugs were not analyzed. However, to the best of our knowledge, the present work is the first to show the impact of glycemic control as represented by $\mathrm{HbA}_{1 \mathrm{c}}$ levels on cancer treatment outcomes in LACC patients receiving NACT and radical hysterectomy. Moreover, our large sample size allowed us to provide reliable evidence to inform clinical practice.

\section{Conclusions}

In summary, our findings suggest that poor glycemic control prior to $\mathrm{NACT}$, as indicated by elevated $\mathrm{HbA}_{1 \mathrm{C}}$ levels, is independently associated with an increased risk of tumor recurrence and mortality for LACC patient. We also present evidence that poorly controlled DM is an independent predictor of poor response to NACT. Given these results, we believe that the proper management of diabetes may present an opportunity for improving survival outcomes for LACC patients. Our findings should be confirmed prospectively. Future randomized trials are also warranted to investigate whether targeting glycemic control offers oncological benefits for diabetic LACC patients.

\section{Additional files}

Additional file 1: Figure S1. Guide for follow-up and telephone interview. (EPS $650 \mathrm{~kb}$ )

Additional file 2: Table S1. Univariate and multivariate Cox analysis of prognostic factors associated with survival for diabetic patients with locally advanced cervical cancer who underwent neoadjuvant chemotherapy and radical hysterectomy. (DOCX $23 \mathrm{~kb})$

\section{Abbreviations}

BMI: Body mass index; Cl: Confidence interval; CR: Complete response; CSS: Cancer-specific survival; DM: Diabetes mellitus; FIGO: International Federation of Gynecology and Obstetrics; $\mathrm{HbA}_{1 c}$ : Hemoglobin $\mathrm{A}_{1 \mathrm{c} ;}$; HR: Hazard ratio; LACC: Locally advanced cervical cancer; LVSI: Lymphatic vascular space invasion; NACT: Neoadjuvant chemotherapy; OR: Odds ratio; OS: Overall survival; RFS: Recurrence-free survival

\section{Acknowledgements}

Not applicable.

\section{Funding}

There are no funding sources for this study.

\section{Availability of data and materials}

The datasets used and/or analysed during the current study are available from the corresponding author on reasonable request.

\section{Authors' contributions}

$\mathrm{JL}$ : conception and design of study, analysis and interpretation of data, drafting of original manuscript, editing final manuscript, approval of final version of the manuscript. NYN: conception and design of study, data curation, analysis and interpretation of data, editing final manuscript, approval of final version of the manuscript. QXR: data curation, analysis and interpretation of data, drafting of original manuscript, editing final manuscript, approval of final version of the manuscript. RC: data curation, analysis and interpretation of data, revising final manuscript, approval of final version of the manuscript. LJW: conception and design of study, interpretation of data, critical revision of final manuscript, approval of final version of the manuscript. ZQL: conception and design of study, interpretation of data, critical revision of final manuscript, approval of final version of the manuscript.

\section{Ethics approval and consent to participate}

Institutional Review Board approval was obtained from Sun Yat-sen Memorial Hospital and People's Hospital of Shaolin District. Written informed consent was obtained from each patient in this study.

\section{Consent for publication}

Not applicable.

\section{Competing interests}

The authors declare that they have no competing interests.

\section{Publisher's Note}

Springer Nature remains neutral with regard to jurisdictional claims in published maps and institutional affiliations.

\section{Author details}

'Department of Gynecologic Oncology, Sun Yat-sen Memorial Hospital, Sun Yat-sen University, 102 Western Yanjiang Road, Guangzhou 510120, People's Republic of China. ${ }^{2}$ Key Laboratory of Malignant Tumor Gene Regulation and Target Therapy of Guangdong Higher Education Institutes, Sun Yat-sen University, Guangzhou 510120, People's Republic of China. ${ }^{3}$ Department of Obstetrics and Gynecology, People's Hospital of Shaolin District, Luohe 462300, People's Republic of China. ${ }^{4}$ Health center, Sun Yat-sen Memorial Hospital, Sun Yat-sen University, Guangzhou 510120, People's Republic of China.

Received: 6 February 2017 Accepted: 28 July 2017

Published online: 03 August 2017

\section{References}

1. Xu T. Chinese anti-cancer association as a non-governmental organization undertakes systematic cancer prevention work in China. Chin J Cancer Res. 2015:27:423-7.

2. Yu S, Yang CS, Li J, You W, Chen J, Cao Y, et al. Cancer prevention research in China. Cancer Prev Res (Phila). 2015:8:662-74.

3. Goss PE, Strasser-Weippl K, Lee-Bychkovsky BL, Fan L, Li J, Chavarri-Guerra Y, et al. Challenges to effective cancer control in China, India, and Russia. Lancet Oncol. 2014;15:489-538.

4. Weng J, Pozzilli P. Hot topics on diabetes in China. Diabetes Metab Res Rev. 2015;31:779-80.

5. Ko C, Chaudhry S. The need for a multidisciplinary approach to cancer care. J Surg Res. 2002;105:53-7.

6. Li J, Wu MF, Lu HW, Zhang BZ, Wang LJ, Lin ZQ. Impact of hyperglycemia on outcomes among patients receiving Neoadjuvant chemotherapy for bulky early stage cervical cancer. PLoS One. 2016;11:e0166612.

7. Tai YS, Chen CH, Huang CY, Tai HC, Wang SM, Pu YS. Diabetes mellitus with poor glycemic control increases bladder cancer recurrence risk in patients with upper urinary tract urothelial carcinoma. Diabetes Metab Res Rev. 2015:31:307-14

8. Kaneda K, Uenishi T, Takemura S, Shinkawa H, Urata Y, Sakae M, et al. The influence of postoperative glycemic control on recurrence after curative resection in diabetics with hepatitis $C$ virus-related hepatocellular carcinoma. J Surg Oncol. 2012;105:606-11.

9. Lee H, Kuk H, Byun SS, Lee SE, Hong SK. Preoperative glycemic control status as a significant predictor of biochemical recurrence in prostate cancer patients after radical prostatectomy. PLoS One. 2015;10:e124761. 
10. Erickson K, Patterson RE, Flatt SW, Natarajan L, Parker BA, Heath DD, et al. Clinically defined type 2 diabetes mellitus and prognosis in early-stage breast cancer. J Clin Oncol. 2011;29:54-60.

11. Siddiqui AA, Spechler SJ, Huerta S, Dredar S, Little BB, Cryer B. Elevated $\mathrm{HbA1c}$ is an independent predictor of aggressive clinical behavior in patients with colorectal cancer: a case-control study. Dig Dis Sci. 2008;53:2486-94

12. Sarma AV, Hotaling J, Dunn RL, Cleary PA, Braffett BH, Kim C, et al. Poor glycemic control is associated with reduced prostate specific antigen concentrations in men with type 1 diabetes. J Urol. 2015;193:786-93.

13. Lee YY, Choi CH, Kim CJ, Song TJ, Kim MK, Kim TJ, et al. Glucose as a prognostic factor in non-diabetic women with locally advanced cervical cancer (IIB-IVA). Gynecol Oncol. 2010;116:459-63.

14. Chen $\mathrm{W}$, Zheng $\mathrm{R}$, Zeng $\mathrm{H}$, Zhang $\mathrm{S}$. The incidence and mortality of major cancers in China, 2012. Chin J Cancer. 2016;35:73.

15. Koh WJ, Greer BE, Abu-Rustum NR, Apte SM, Campos SM, Cho KR, et al. Cervical cancer, version 2.2015. J Natl Compr Cancer Netw. 2015;13:395-404. quiz

16. Ye Q, Yuan HX, Chen HL. Responsiveness of neoadjuvant chemotherapy before surgery predicts favorable prognosis for cervical cancer patients: a meta-analysis. J Cancer Res Clin Oncol. 2013;139:1887-98.

17. Boronow RC. The bulky $6-\mathrm{cm}$ barrel-shaped lesion of the cervix: primary surgery and postoperative chemoradiation. Gynecol Oncol. 2000;78:313-7.

18. Hacker NF, Wain GV, Nicklin JL. Resection of bulky positive lymph nodes in patients with cervical carcinoma. Int J Gynecol Cancer. 1995;5:250-6.

19. Kupets $R$, Thomas $G M$, Covens $A$. Is there a role for pelvic lymph node debulking in advanced cervical cancer? Gynecol Oncol. 2002;87:163-70.

20. Buda A, Lissoni AA, Floriani I, Biagioli E, Gerardi C, Bonazzi C, et al. Longterm clinical benefits of Neoadjuvant chemotherapy in women with locally advanced cervical cancer: validity of pathological response as surrogate endpoint of survival. Int J Gynecol Cancer. 2015;25:1468-75.

21. Cai Q, Luo X, Liang Y, Rao H, Fang X, Jiang W, et al. Fasting blood glucose is a novel prognostic indicator for extranodal natural killer/T-cell lymphoma, nasal type. Br J Cancer. 2013;108:380-6.

22. Sonabend RY, McKay SV, Okcu MF, Yan J, Haymond MW, Margolin JF. Hyperglycemia during induction therapy is associated with poorer survival in children with acute lymphocytic leukemia. J Pediatr. 2009;155:73-8.

23. Wu W, Merriman K, Nabaah A, Seval N, Seval D, Lin H, et al. The association of diabetes and anti-diabetic medications with clinical outcomes in multiple myeloma. Br J Cancer. 2014;111:628-36.

24. Ahn JH, Jung SI, Yim SU, Kim SW, Hwang EC, Kwon DD. Impact of Glycemic control and Metformin use on the recurrence and progression of nonmuscle invasive bladder cancer in patients with diabetes mellitus. J Korean Med Sci. 2016;31:1464-71.

25. Takatori E, Shoji T, Omi H, Kagabu M, Miura F, Takeuchi S, et al. Analysis of prognostic factors for patients with bulky squamous cell carcinoma of the uterine cervix who underwent neoadjuvant chemotherapy followed by radical hysterectomy. Int J Clin Oncol. 2015;20:345-50.

26. American DA. Diagnosis and classification of diabetes mellitus. Diabetes Care. 2011;34(Suppl 1):S62-9.

27. Buell C, Kermah D, Davidson MB. Utility of A1C for diabetes screening in the 19992004 NHANES population. Diabetes Care. 2007;30:2233-5.

28. Yang W, Lu J, Weng J, Jia W, Ji L, Xiao J, et al. Prevalence of diabetes among men and women in China. N Engl J Med. 2010;362:1090-101.

29. Warburg O. On the origin of cancer cells. Science. 1956;123:309-14.

30. Ryu TY, Park J, Scherer PE. Hyperglycemia as a risk factor for cancer progression. Diabetes Metab J. 2014;38:330-6.

31. Belfiore A, Frittitta L, Costantino A, Frasca F, Pandini G, Sciacca L, et al. Insulin receptors in breast cancer. Ann N Y Acad Sci. 1996;784:173-88

32. Papa V, Belfiore A. Insulin receptors in breast cancer: biological and clinical role. J Endocrinol Investig. 1996;19:324-33.

33. Newschaffer CJ, Penberthy L, Desch CE, Retchin SM, Whittemore M. The effect of age and comorbidity in the treatment of elderly women with nonmetastatic breast cancer. Arch Intern Med. 1996;156:85-90.

34. Bergman L, Dekker G, van Kerkhoff EH, Peterse HL, van Dongen JA, van Leeuwen FE. Influence of age and comorbidity on treatment choice and survival in elderly patients with breast cancer. Breast Cancer Res Treat. 1991; 18:189-98.

35. Martinez-Huedo MA, Lopez de Andres A, Hernandez-Barrera V, CarrascoGarrido P, Martinez Hernandez D, Jimenez-Garcia R. Adherence to breast and cervical cancer screening in Spanish women with diabetes: associated factors and trend between 2006 and 2010. Diabetes Metab. 2012;38:142-8.

\section{Submit your next manuscript to BioMed Central and we will help you at every step:}

- We accept pre-submission inquiries

- Our selector tool helps you to find the most relevant journal

- We provide round the clock customer support

- Convenient online submission

- Thorough peer review

- Inclusion in PubMed and all major indexing services

- Maximum visibility for your research

Submit your manuscript at www.biomedcentral.com/submit 